\title{
Temporary polyurethane-covered nitinol endoprosthesis forthe bulbous urethra stricture treatment
}

\begin{abstract}
The incidence of urethral strictures and their recurrences is high. The effectiveness of optical urethrotomy is insufficient. Reconstructive urethroplasty is traumatic and accompanied by a prolonged period of rehabilitation. The results of metal endourethral stents using were unsatisfactory due to the granulation tissue ingrowth through the metallic threads, stent incrustation, and migration. Authors present the personal experience of bulbous urethral strictures treatment in 32 patients, who underwent visual optical urethrotomy with temporary placement of a new generation polyurethane-covered nitinol stents. After removing the stents from 4 to 10 months after implantation, a stable effect of urethral lumen preserving was achieved. The stricture recurrence occurred in 3 cases $(9,4 \%) 3-5$ month following the stent removal. Clinical success was $80,6 \%$. Authors consider the stent implantation as an alternative adjunctive treatment of the patients with urethral strictures.
\end{abstract}

Keywords: urethral strictures, visual optical urethrotomy, ureteral endoprostheses, endoscopic forceps, retrograde urethrography, fibro-urethroscopy
Volume 6 Issue I - 2018

\author{
Kurbatov DG,' Martov AG, ${ }^{2}$ Andreev Yu G, ${ }^{3}$ \\ Raff $\mathrm{LS}^{3}$ \\ 'Department of Urology, City Clinical Hospital, Russia \\ 2Minimally Invasive Technologies, Zheleznodorozhnyi, Russia \\ ${ }^{3}$ Department of Andrology and Urology, Endocrinological \\ Research Center, Russia
}

Correspondence: DG Kurbatov, Department of Andrology and Urology, Endocrinological Research Center, I I 7036,

Moscow, Russia, Tel 7 (985) 840-70-50,

Email kurbatov.d@mail.ru

Received: November 17, 2017| Published: January 09, 2018

\section{Introduction}

Surgical treatment of the urethral strictures remains actual. The commonly used measures are reconstructive urethroplasty and visual optical urethrotomy (VOU). But VOU is characterized by a high rate of stricture recurrence, and therefore high hopes were placed on internal ureteral endoprostheses (stents), thatwere implanted after urethrotomy. Various complications have also been noted after metal stent implantation: salt incrustation, migration, ingrowth of the granulation tissue through the metallic threads into the lumen. However, a new generation of urethral stents appeared, consisting of a metal mesh tubular frame made of titanium-nickel alloy completely covered with a polyurethane film. In the polyurethane-coated endoprostheses there are no conditions for a connective tissue to grow into the lumenof the stent. Recently, an experience with temporarily coated stents for the treatment of bulbous urethral stricture was presented by M Culha et al. ${ }^{1}$ Clinically the success was achieved in $81,4 \%$.

We have personal experience of temporary nitinol stents covered with polyurethane film implantation (manufactured by "MIT" Ltd, Russia). 32 patients $23-58$ y.o. ( $36 \pm 12$ ) with bulbous urethra strictures were treated during the period from 2014 to 2017. The etiological factors of the strictures were - trauma (11 patients), transurethral resection of BPH (8), urethral infections (10), in 3 cases the cause could not be established. The diagnosis was confirmed with retrograde urethrography, uroflowmetry and, if necessary, fibro-urethroscopy. Qmax was $5.3(4.1-8.2) \mathrm{ml} / \mathrm{s}$, the urethral stricture length was 2.5 $(1.4-4.6) \mathrm{cm}$.

An internal VOU was performed with a cold knife and endoprostheses were positioned into the zone of the transectedstricture. Patients freely urinated in the postoperative period and noted a significant increase in the urine stream: 2-3 days after the operation Qmax was 20 (15-24) ml/s. There were no cases of the migration of the prostheses. 29 potent before our surgery men were able to restore satisfactory sexual activity one week after stents implantation.None of the patients complained of weakening in the flow of urine during the entire period of the implant in the body.
Stents were removed in all patients 4-10 months after installation (median value of stent being positioned in the urethra was 5,5 month). Explantation performed using endoscopic forceps or hookunder local anesthesia.

The results of our investigations show that it is possible to get stable preservation of the urethral lumen when the stent remains within the lumen not less than 4 months. This is minimal time span for a creation of the neourethra.The final withdrawal of the endoprosthesis is unavoidable step because completely formed neourethra preserves its lumen stable and further remaining of the foreign body is unwelcome because it can be followed by incrustation, discomfort or infection.

The recurrence of the stricture occurred in 3 men $(9,4 \%)$ during 3-5 month after endoprosthesis removal. Patients underwent buccal urethroplasty further.All other 29 patients $(80,6 \%)$ in $1-3$ years after treatment had no recurrence of the stricture. Control uroflowmetry performed in 14 men and Qmax (median) was 18,7 (16-23)ml/sec.

The advantages of the urethra stenting technology: minimal invasive technique, immediate result of urination restoring, short period of hospitalization and rehabilitation. It looks like good alternative to conventional reconstructive operations.

\section{Funding}

None.

\section{Acknowledgements}

None.

\section{Conflicts of interest}

There is no conflict of interest exists.

\section{References}

1. Culha M, Ozkuvanci U, Ciftci S, et al. Management of recurrent bulbar urethralstricture-a 54 patients study with Allium bulbar urethral stent (BUS). Int J ClinExp Med. 2014;7(10):3415-3419. 